\title{
Numerical simulation on the aerodynamic characteristics effect of ribs
}

\section{acting on the stay cable}

\author{
Huang Yifeng ${ }^{1, a^{*}}$, Yang Jixin ${ }^{2}$ \\ ${ }^{1}$ School of Transportation, Wuhan University of Technology, wuhan, China \\ ${ }^{2}$ School of Railway Tracks and Transportation, East China of Jiao Tong University, Nanchang \\ China \\ a aminghyf@126.com
}

Keywords: stay cable; rib; numerical simulation; aerodynamic characteristics

Abstract:The cable wind-induced vibration of long span cable-stayed bridge is one of the key factors causing serious damage to the bridge. The ribs setting on the surface of the stay cable are one of the aerodynamic damping measures to restrain its wind-induced vibration. As the surface morphology of the stay cable changes, its aerodynamic characteristics will change accordingly. The numerical simulations are carried out on the cables with ribs of different size using FLUENT, calculating the three force coefficients respectively, then the results were compared with the stay cable with smooth surface. The result shows that, compared with the stay cable with smooth surface, the tendency of the drag coefficient and lift coefficient of the stay cable with ribs is inapparent, while the lift moment coefficient reduced significantly. The effect of ribs height on the three force coefficients is not significant.

\section{Introduction}

With the increasing span of the cable-stayed bridge, the length of stay cable become longer and longer. The wind-induced vibration mechanism and vibration control measures of stay cables have become an important research. The cable wind-induced vibration of long span cable-stayed bridge is one of the key factors causing serious damage to the bridge. There are three main wind vibration suppression measures for stay cable, aerodynamic measures, auxiliary cable measures and aerodynamic damping measure ${ }^{[1]}$. The wind tunnel test had verified that the ribs setting on the surface of the stay cable may play an inhibitory effect on its wind-induced vibration ${ }^{[2-3]}$. The Tokyo Kobe Bridge in Japan (whose main span is $485 \mathrm{~m}$ ) used the vibration-suppression measure for the first time, the fact proved that the measure can get good results. Owing to its good effect of vibration-suppression and simple production method, the measure has good practical value.

Due to the aerodynamic damping mechanism of the rib acting on stay cable is very complicated, the current theoretical analysis is not deep enough. In order to determine the wind vibration damping effect by the rib and the aerodynamic characteristics effects of setting ribs on the cable, the numerical wind tunnel tests are carried out on the cables with ribs of different size using FLUENT, calculating the three force coefficients respectively, then the results were compared with the stay cable with smooth surface, which have get some helpful conclusions.

\section{Select the computing model of the cable}

Rain-wind-induced vibration of stay cables is one of the wind-induced vibration who has the 
maximum amplitude and the most serious harm. And existing literature ${ }^{[1] 5]}$ shows that, when the cable inclination $\alpha$ is about $30^{\circ}$ and the wind angle $\beta$ is approximately $30^{\circ} \sim 35^{\circ}$, the wind-induced vibration is the most likely to occur. So the computing model of the cable is selected whose inclination $\alpha=30^{\circ}$ and its wind angle $\beta=35^{\circ}$, which is shown in Fig.1.

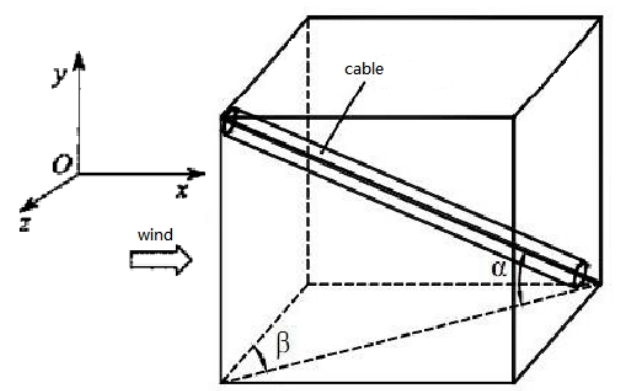

Fig. 1 Cable inclination $\alpha$ and wind angle $\beta$

A rib is set every $30^{\circ}$ along the circumference whose width is $b=16 \mathrm{~mm}$ and height is $h=4,8$, $12 \mathrm{~mm}$ separately. Then the rib interval angle $\delta=30^{\circ}$ and the total number of ribs is six. As shown in Fig.2.
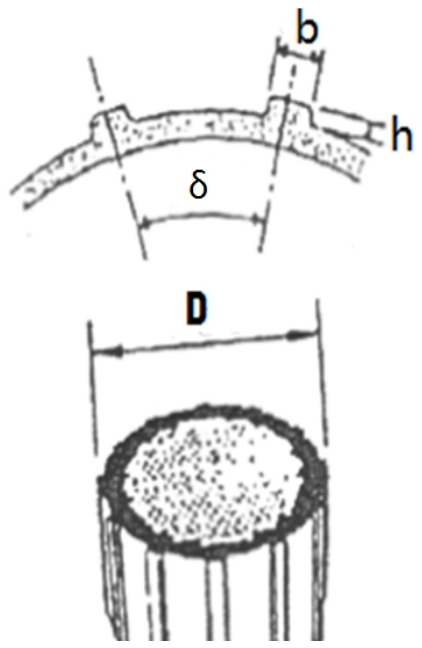

Fig.2 the parameter of stay cable with ribs

In order to verify the aerodynamic characteristics effect of the ribs acting on the stay cable, the following four working conditions have carried on. As shown in Tab.1.

Tab. 1 the parameter of ribs of several working conditions

\begin{tabular}{ccccc}
\hline Working condition & $\begin{array}{c}\text { the width of } \\
\text { rib }\end{array}$ & $\begin{array}{c}\text { the height of } \\
\text { rib }\end{array}$ & $\begin{array}{c}\text { the rib interval } \\
\text { angle }\end{array}$ & comments \\
\hline $\begin{array}{c}b / \mathrm{mm} \\
1^{\text {st }} \text { Working condition }\end{array}$ & 0 & $\begin{array}{c}h / \mathrm{mm} \\
\delta /{ }^{\circ}\end{array}$ & 0 & $\begin{array}{c}\text { Smooth } \\
\text { cable }\end{array}$ \\
$2^{\text {nd }}$ Working & 16 & 0 & $30^{\circ}$ & \\
condition & & 4 & & \\
$3^{\text {rd }}$ Working condition & 16 & 8 & $30^{\circ}$ & \\
$4^{\text {th }}$ Working condition & 16 & 12 & $30^{\circ}$ & \\
\hline
\end{tabular}


Take the cable diameter $D=0.2 \mathrm{~m}$, the projected length of the cable in the height direction is $18 D$. The computational domain is:Length $\times$ Width $\times$ Height $=(50 D+$ the projected length of the cable in the length direction $) \times(20 D+$ the projected length of the cable in the width direction $) \times 18 D$. The distance from entrance boundary and exit boundary to the cable center is $10 \mathrm{D}$ and $40 \mathrm{D}$ respectively. The distance from left and right boundaries to the cable center is $10 \mathrm{D}$. The diagram of model is shown in Fig.2. Existing research shows that ${ }^{[8]}$ only when the wind speed is 8 to $18 \mathrm{~m} / \mathrm{s}$ the wind-rain vibration occurs, so the wind speed is set as $15 \mathrm{~m} / \mathrm{s}$.

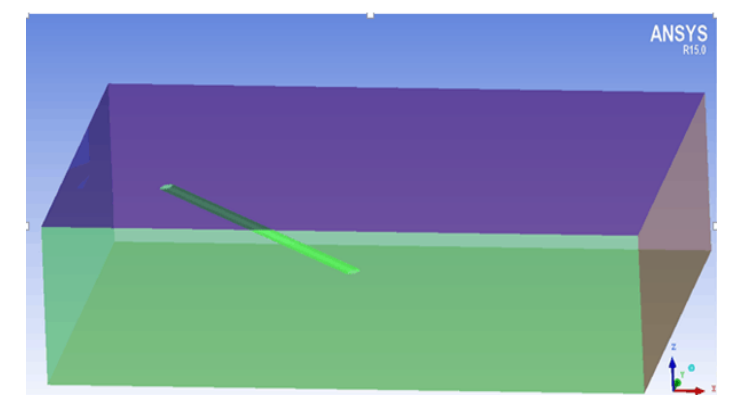

Fig.3 The computational domain

\section{Meshing}

Then the computing model is meshed by structural grid and the flow domain around the cable is thicken. The diagram of structural grid is shown in Fig.4. Due to the limitation of space, Fig.4 only shows the grid of the $4^{\text {th }}$ working condition. The grids of the remaining three working conditions are similar with the $4^{\text {th }}$ working condition.

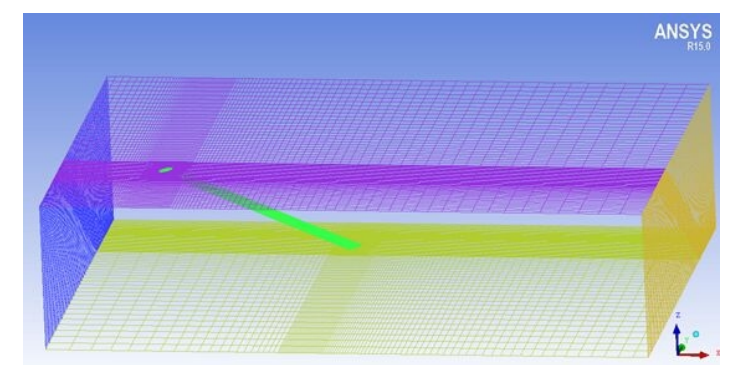

(a) the frame-line diagram of structuring grid

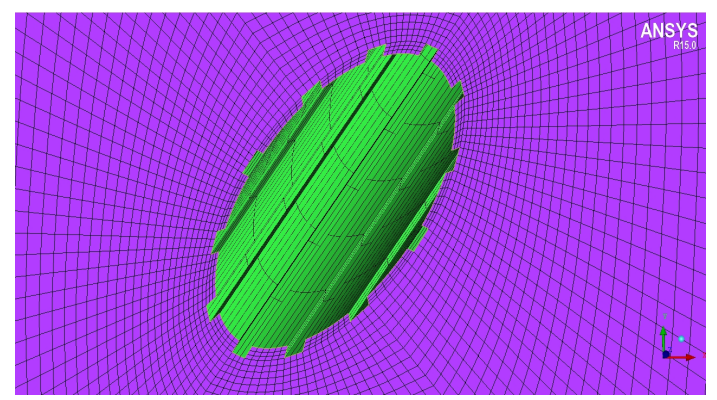

(b) the structuring grid of the stay cable with ribs (the $4^{\text {th }}$ working condition)

Fig.4 the structuring grid of the stay cable with ribs 


\section{Computing result}

The computing results are shown in Fig.5.

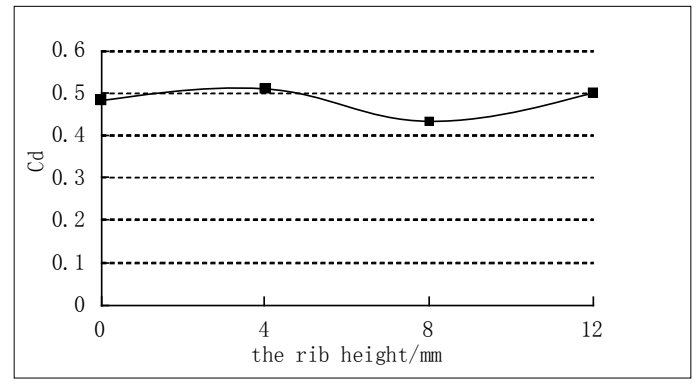

(a) the drag coefficient

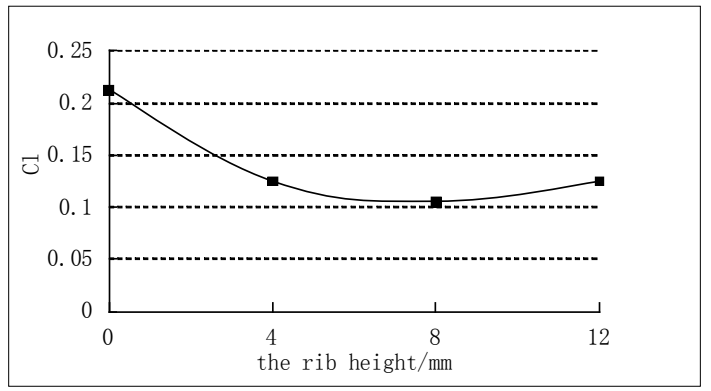

(b) the lift coefficient

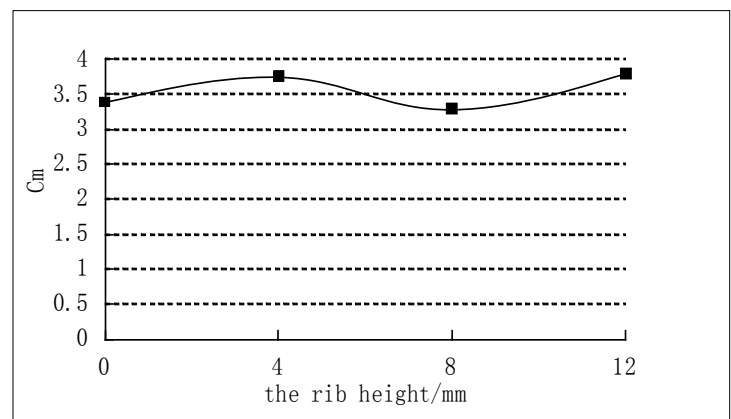

(c) the lift moment coefficient

Fig.5 the tendency chart of the three force coefficients along the rib height $\left(\delta=30^{\circ}\right)$

The Fig. 5 shows that:

(1) The effect of ribs height on the drag coefficient and lift moment coefficient is not significant. With the increase of rib height, the drag coefficient and lift moment coefficient change slightly, but the changing direction is not clear, sometimes increase or decrease. The drag coefficient and lift moment coefficient maintain $0.48 \pm 10 \%$ and $3.4 \pm 10 \%$ basically. May be due to the symmetric arrangement of the rib setting on stay cable, the rib height has no effect on lift coefficient basically.

(2) The lift coefficients of the cable with different ribs are maintain around 0.125 , compared with the cable with smooth surface, the lift coefficient sharply reduced by $41.3 \%$.

\section{Conclusion}

The numerical simulations are carried out on the cables with ribs of different size using FLUENT, calculating the three force coefficients respectively, then the results were compared with the stay cable with smooth surface. The result shows that:

(1) Compared with the stay cable with smooth surface, the tendency of the drag coefficient and 
lift moment coefficient are not obvious after setting different ribs.

(2) Compared with the stay cable with smooth surface, the lift coefficient reduced sharply.

(3) The effect of ribs height on the three force coefficients are not significant.

\section{Acknowledgments}

It is a project supported by Jiangxi Provincial Department of Science and Technology

(20151BAB206058)、Jiangxi Provincial Education Development (GJJ14382) and East China Jiao Tong University （14GD04）.

\section{References}

[1] Li Longan, Miao Runchi, Qu Aiping. Research on wind-induced vibration control of super long stay cables[J]. Earthquake Engineering and Engineering Vibration, 2014, 34 (3):206-211. (in Chinese)

[2] Li Zhe, Liu Jiangxin. Influence of aerodynamic measure on wind load and structural response of stayed cable[J]. Journal of Architecture and Civil Engineering, 2010，27 (3):89-93. (in Chinese )

[3] Olivier Flamand. Rain-wind induced vibration of cables[J]. Journal of Wind Engineering and Industrial Aerodynamic, 1995, 57 (1) :353-362.

[4] Hikami Y, Shiraishi N. Rain-wind induced vibrations of cables in cable stayed bridges[J]. Journal of Wind Engineering and Industrial Aerodynamics， 1988，29 (1-3):409-418.

[5] Gu Ming, Du Xiaoqin. Experimental investigation of rain-wind-induced vibration of cables in cable-stayed bridges and its mitigation[J]. Journal of Wind Engineering and Industrial Aerodynamics, 2005, 93 (1):79-95.

[6] Yasui H, Marukawa H, Katagiri J, et al. Study of wind-induced response of long-span structure[J]. Journal of Wind Engineering and Industrial Aerodynamics， 1999， 83

(1-3): :277-288. 